\title{
Automated portfolio rebalancing: Automatic erosion of investment performance?
}

\author{
Matthias Horn ${ }^{1}\left[\right.$. Andreas Oehler ${ }^{2}$
}

Revised: 24 August 2020 / Published online: 22 September 2020

(c) The Author(s) 2020

\begin{abstract}
Robo-advisers enable investors to establish an automated rebalancing strategy for a portfolio usually consisting of stocks and bonds. Since households' portfolios additionally include further frequently tradable assets like real estate funds, articles of great value and cash(-equivalents), we analyze whether households would benefit from a service that automatically rebalances a portfolio which additionally includes the latter assets. In contrast to previous studies, this paper relies on realworld household portfolios, which are derived from the German central bank's (Deutsche Bundesbank) Panel on Household Finances (PHF)-Survey. We compute the portfolio performance increase/decrease that households would have achieved by employing rebalancing strategies instead of a buy-and-hold strategy in the period from September 2010 to July 2015 and analyze whether subsamples of households with certain sociodemographic and socioeconomic characteristics would have benefited more from portfolio rebalancing than other household subsamples. The empirical analysis shows that the analyzed German households would not have benefited from an automated rebalancing service and that no subgroup of households would have significantly outperformed another subgroup in the presence of rebalancing strategies.
\end{abstract}

Keywords Household finance $\cdot$ Robo-advisor $\cdot$ Portfolio rebalancing $\cdot$ Fixed-weight asset strategy

JEL Classification D14 · G11 · G23 · G41

This paper uses data from the Deutsche Bundesbank Panel on Household Finances. The results published and the related observations and analysis may not correspond to results or analysis of the data producers. We would like to thank Marielle de Jong (the editor) and an anonymous referee for valuable comments and Deutsche Bundesbank, especially Martin Eisele, for providing the dataset of the PHF-Survey. In addition, we would like to thank Stefan Wendt from Reykjavik University in Reykjavik, Iceland, participants of the 30th European Conference on Operational Research, Dublin, Ireland, participants of the 2019 FMA European Conference, Glasgow, Scotland, participants of the 2019 Annual Meeting Academy of Financial Services, Minneapolis, participants of the 88th International Atlantic Economic Conference, Miami, participants of the 82nd Annual Business Researcher Conference, Frankfurt, Germany, and seminar participants at Bamberg University in Bamberg, Germany, for helpful comments and suggestions. All remaining errors are our own.

Electronic supplementary material The online version of this article (https://doi.org/10.1057/s41260-020-00183-0) contains supplementary material, which is available to authorized users.

Matthias Horn

matthias.horn@uni-bamberg.de

1 Department of Finance, Bamberg University, Kaerntenstrasse 7, 96045 Bamberg, Germany

\section{Introduction}

Rebalancing investments, i.e., keeping the relative portfolio weights of different asset classes with calendar-based and/or threshold-based strategies stable (see Donohue and Yip 2003), are associated with both locking in a portfolio's risk exposure at an intended level (see, e.g., Tsai 2001) and the ability to buy assets at low and sell them at high prices (see, e.g., Bouchey et al. 2012). Nevertheless, only a minority of households actually rebalances their portfolios (see, e.g., Bonaparte and Cooper 2009; Brunnermeier and Nagel 2008). Possible reasons for households' inertia (particularly for households with low portfolio values) are that rebalancing strategies cause transaction and monitoring costs which make a simple buy-and-hold strategy more appealing.

2 Chair of Finance, Bamberg University, Kaerntenstrasse 7, 96045 Bamberg, Germany 
With the emergence of robo-advisers, however, households got a tool at hand which enables them to establish a rebalancing strategy without the need to care about the investments by themselves. In brief, robo-advisers are an automated investment service that helps investors to establish a portfolio of stocks and bonds under consideration of the investors' perceived risk tolerance. Thereafter, roboadvisers rebalance this portfolio to offset the variations induced by asset price movements in order to keep the portfolio's ratio of stocks and bonds constant over time (see, e.g., Oehler 2015; Oehler et al. 2016). ${ }^{1}$ Robo-advisers usually charge their customers only the second part of the servicethe rebalancing of the portfolio-through a management fee of .15 to $.50 \%$ per year (see, e.g., Ferri 2015).

The first part of their service-helping households to establish a diversified portfolio of stock and bond exchange traded funds-is free of charge although this service can significantly enhance households' risk-return position compared to a portfolio of individual stocks and bonds (see Oehler and Wanger 2019). Furthermore, the pure presence of this service-just like a financial advisor-might encourage some households that do not participate in risky asset markets yet (e.g., because the households feel not competent enough (e.g., Gennaioli et al. 2015) or mistrust financial markets (e.g., Guiso et al. 2008)) to invest in some risky assets at all (see Foerster et al. 2017) and therefore enhance these households' investment performance. We assume that robo-advisers do not charge this service because they provide it only once to a household. In addition, it is fairly easy for interested households to establish a diversified portfolio of exchange traded funds by themselves as consumer organizations provide easy to implement portfolios with preselected funds. The remaining households probably do not perceive that they need financial advice and, hence, are not the target group of the robo-advisers (since after all the clients of robo-advisers need to actively seek for financial advice to go to the robo-advisor). It is therefore more interesting to focus on the rebalancing service of robo-advisers as it is unclear whether households benefit from existing portfolio rebalancing services. Moreover, an analysis of this question can reveal new directions for innovations of roboadvisers that help households to increase their investment performance.

Particularly with regard to the considered assets, one could ask why the providers of robo-advice keep their business model so narrow. Field data show that households' portfolios include more frequently tradable assets than stocks and bonds, e.g., real estate funds, articles of great value and cash(-equivalents). But there are no robo-advisers so far that

\footnotetext{
${ }^{1}$ Consequently, robo-advisers' rebalancing reflects a fixed-weight asset strategy, which is also pursued by some multi-asset funds.
}

offer rebalancing strategies covering all these asset classes. Furthermore, there are no studies that analyze the benefits of such a (potential) service from households' perspective. Hence, it is unclear whether households generally would benefit from such a rebalancing service or whether-comparable to active fund management- the portfolio management services and the associated fees would harm households' investment performance.

This study addresses this gap in the literature by analyzing the outcomes of a hypothetical robo-advisor that rebalances households' investments in the asset classes stocks, bonds, real estate funds, articles of great value and cash (-equivalents). Specifically, the aim of this study is to shed light on the question whether it is likely that households benefit from a service that automatically rebalances their investments in the latter asset classes. It is important to notice at this point that this study deliberately employs a descriptive and not a normative approach. The rationale is that normative approaches have to use assumptions regarding households' utility functions, investment goals and the return distribution of the underlying asset classes. Results of these analyses are hardly applicable for households because they are not able to provide their utility function and additionally use heuristics such as mental accounting, i.e., households assign certain goals to their investments (e.g., having a certain spendable amount of money when entering retirement) rather than checking whether their investments are in line with a utility function that the households do not know anyway. This, however, does not mean that households would willingly accept an inefficient portfolio. Instead, investing in a mean-variance efficient portfolio is the preferred way to reach the investment goal. Therefore, we calculate the return, returns' standard deviation, Sharpe ratio and adjusted Sharpe ratio that households would have achieved by employing rebalancing strategies in the period from September 2010 to July 2015, and compare these values with the outcomes of a buy-and-hold strategy. The analyzed time period starts in September 2010 when the Deutsche Bundesbank started its interviews for the PHF-Survey among 3565 German households. The dataset of the PHF-Survey includes the absolute amount of money that an interviewed household invested per asset class. Hence, one main contribution of this study is that rebalancing strategies are applied to the established asset mixes of real households. This also enables us to analyze whether certain asset mixes were more suitable for a rebalancing strategy than others. Since households' asset mixes partially depend on households' characteristics, the analysis is suitable to assess whether a subsample of households with certain sociodemographic and socioeconomic characteristics would have benefited more from portfolio rebalancing than other households. In an extreme case rebalancing may lead to a redistribution of wealth from one subgroup of households to another if the first subgroup suffers 
from rebalancing while the second benefits from the same strategy.

This study contributes to the literature on the performance of rebalancing and fixed-weight asset strategies and the potential benefits of robo-advisers in three ways. First, this is, to the best of our knowledge, the first study that applies fixed-weight asset strategies on real households' asset mixes instead of simulating a number of hypothetical asset mixes. Second, the fixed-weight asset strategies are applied on more asset classes than in previous studies. Thereby, we suggest an approach to operationalize and implement a fixed-weight asset strategy to more than three asset classes. Third, the computation of the portfolios' adjusted Sharpe ratios makes it possible to assess whether rebalancing leads to a more favorable return distribution (in terms of the distributions' skewness and kurtosis) compared to a buy-and-hold strategy.

The results of the empirical analysis show that the analyzed German households would not have benefited from an automated rebalancing service compared to a buy-and-hold strategy. Furthermore, there is no subsample of households with certain sociodemographic or socioeconomic characteristics that shows significantly higher benefits/losses through rebalancing than other subsamples. Although asset markets were almost throughout in a bullish phase in the observation period (which could maybe lead to an underestimation of the benefits of portfolio rebalancing), the findings clarify that automated rebalancing is not a silver bullet to boost portfolio efficiency. Moreover, returns of all the included asset classes showed on average significant positive returns during the last 120 years (see, e.g., Simson and Spaenjers 2015) suggesting that bullish markets are what long term investors (the customer target group of robo-advisers) usually should expect. Hence, our findings should be interpreted as substantiation that reasonable (e.g., yearly) monitoring frequencies and allocation thresholds are sufficient to control households' portfolio risk and as an indication that households may increase their portfolio performance by avoiding the portfolio management services and the associated fees of rebalancing services.

The remainder of the study is organized as follows. In "Related literature" section, the related literature on the performance of rebalancing and fixed-weight asset strategies is reviewed. "Data and methodology" section contains a description of the PHF dataset provided by Deutsche Bundesbank and the methodology of the analysis. The results and robustness checks are provided in "Results" section. "Discussion and conclusion" section discusses and concludes the analysis.

\section{Related literature}

The emergence of robo-advisers helps households to implement a popular advice of practitioners and academics in the field of households finance: to invest in broad market indexes and rebalance the portfolio regularly to harvest the benefits of portfolio diversification (see, e.g., Oehler and Wanger 2019; Jacobs et al. 2014 and the therein cited literature). The background of this advice is that households usually suffer from concentrated portfolios with relatively few stocks (e.g., Goetzmann and Kumar 2008; Polkovnichenko 2005) combined with inefficient security selection and low market timing abilities (e.g. Barber et al. 2009). To eliminate the losses from underdiversification, robo-advisers generally invest in exchange traded funds (ETFs) and certificates on exchange traded indices. ${ }^{2}$

Moreover, regularly rebalancing a portfolio helps to keep the portfolio's risk exposure near the original intended level (see, e.g., Tokat and Wicas 2007). This intention, i.e., to keep the risk exposure stable over time, is most likely rooted in the theoretical predictions of the basic partial equilibrium model by Merton (1969), which puts a household's financial risk-taking in direct relation to household-specific characteristics. If the investors' beliefs and risk aversion remain unchanged over time, the portfolio's risk exposure should be rebalanced back to its original level and should fully offset the variations induced by asset price movements (see Guiso and Sodini 2013, p. 1475). However, if a household pursues a certain investment goal that it wants to reach with a certain probability, e.g., having a certain amount of wealth when entering retirement, such a rebalancing strategy may be unsuitable. Instead, a utility-maximizing strategy would consider the aim and the probability to reach this aim and treat the probability of failing as risk (see Shefrin and Statman 2000). This, however, does not contradict the concept that households only can maximize their utility by investing in a mean-variance efficient portfolio (see Das et al. 2010).

The performance of rebalancing/fixed-weight asset strategies can either be compared to optimizing portfolio choice models (more precisely, to the strategies that can be derived from these models) or to a buy-and-hold strategy. Jacobs et al. (2014) show that fixed-weight asset strategies commonly do not underperform the strategies derived from optimizing portfolio choice models. Their findings support former studies that show an underperformance of the latter strategies compared to naïve $1 / N$ strategies (see, e.g.,

\footnotetext{
$\overline{2}$ On the flipside, the elimination of idiosyncratic risks also eliminates the chance to earn an extraordinary high return through a single rocketing stock, which may be the aim of some investors (see, e.g., Statman 2002). However, we do not assume that this is the aim of households that employ automated rebalancing services.
} 
DeMiguel et al. 2009; Tu and Zhou 2011; Ang 2014; Duchin and Levy 2009 show an outperformance of $1 / N$ strategies for portfolios with less than 30 assets). An opposite opinion is hold by Kritzman et al. (2010) who state an outperformance of optimized portfolios if investors did not rely on obviously implausible assumptions for the assets' expected returns and volatilities. However, since not even professionals are on average able to implement strategies derived from optimization models in an outperforming way (see, e.g., Annaert et al. 2005), most households should be unable to beneficially implement complex optimization models and the resulting strategies. For these households it is rather of interest whether fixed-weight asset strategies outperform a buyand-hold strategy which does not make use of rebalancing.

The stylized advantage of a rebalancing strategy compared to the buy-and-hold strategy is that a rebalancing strategy provides the ability to buy at low prices and sell at high prices (see, e.g., O’Brien 2006; Bouchey et al. 2012). However, in trending markets, investors probably buy before prices get even lower or sell before prices surge further, i.e., rebalancing strategies consciously abstain from exploiting a possible momentum effect ${ }^{3}$ in order to hold the risky share of a portfolio constant, presupposing that households show a constant relative risk aversion ${ }^{4}$ while empirical evidence shows strong indications for a decreasing relative risk aversion (see Calvet and Sodini 2014; Oehler and Horn 2020). Decreasing relative risk aversion in turn would rather correspond to a buy-and-hold than a rebalancing strategy.

Hilliard and Hilliard (2018) analyze the performance of rebalancing strategies with stocks and a risk-free asset. They find that the buy-and-hold strategy outperforms the rebalancing strategies due to the strong performance of the stock market portfolio. Tsai (2001) additionally includes bonds as third asset class and concludes that portfolios benefit from rebalancing. The reason is that buy-and-hold strategies are not sufficiently rewarded with higher returns for the additional risk taken on from increased equity exposure. Subsequent studies support these findings by concluding that rebalancing strategies enhance the Sharpe ratio of a portfolio (see, e.g., Harjoto and Jones 2006; Dichtl et al. 2016). In contrast, Cuthbertson et al. (2015) question the benefits of periodical rebalancing in presence of transaction costs and propose to rebalance not more than necessary to keep a portfolio's asset allocation adequately close to the target percentages over time. A detailed analysis of the role of transaction costs for rebalancing strategies is provided by Donohue and Yip (2003). Hilliard and Hilliard (2018) and Vanguard

\footnotetext{
${ }^{3}$ See, e.g., Asness et al. (2013) for an overview of the momentum effect in different asset classes.

${ }^{4}$ See Arrow (1971) and Pratt (1964) for the concepts of households' relative risk aversion
}

Research (2015) show theoretically and empirically that rebalancing usually leads to lower annualized portfolio volatility but also to lower returns. Dayanandan and Lam (2015) also report no significant gains from rebalancing.

Although particularly studies from the more practitioneroriented literature pledge for the use of rebalancing strategies, their superiority over buy-and-hold strategies is ambiguous from real-world households' point of view. Previous studies on rebalancing have in common that they either rely on predefined asset weights based on anecdotal evidence (e.g., the 60/40 stock-bond portfolio) or on a simulation that employs a broad range of theoretically possible asset weights. However, none of these studies uses asset weights of households' portfolios derived from field data. This can hamper the applicability of the results on households' portfolios. On the one hand, studies using few predefined asset weights are likely to overlook households with an asset mix noticeably different from the predefined asset weights. On the other hand, simulations might include portfolios with asset weights that are hardly observed among households (e.g., a portfolio consisting of $100 \%$ stocks). Furthermore, households' portfolios include more assets than stocks, bonds and cash (see, e.g., Badarinza et al. 2016). Leaving the remaining assets in households' portfolios unconsidered (consequently ignoring the associated portfolio effects) might skew the assessment regarding the usefulness of rebalancing.

The aim of this study is to close these gaps in the literature by answering the question whether households could benefit from a service that rebalances their investments in stocks, bonds, real estate funds, articles of great value and cash(-equivalents). The analysis is based on the assumption that households followed the advice of most academics and the current practice of robo-advisers to invest in ETFs or index certificates that cover a whole asset class instead of holding individual, sometimes hardly tradable assets (e.g., a certificate on an index that covers the development of the asset class articles of great value instead of one antiquity or the like). We think that this assumption is realistic because it is fairly easy for interested households to establish a diversified portfolio of exchange traded funds by themselves as consumer organizations provide easy to implement portfolios with preselected funds. The remaining households who care less about the efficiency of their investment portfolio will anyway not consult robo-advisers and their rebalancing services.

Furthermore the influence of households' asset allocation (e.g., the percentage invested in stocks, see, e.g., Dichtl et al. 2016) on the benefits from portfolio rebalancing is assessed. The importance of a portfolio's initial asset class weights for the future portfolio performance is emphasized by Brinson et al. (1986, 1991, 1995) who show that the asset class weights of US pension plans explain more than $90 \%$ of the 
variation in portfolio returns (see also Ibbotson and Kaplan 2000; Hood 2005 regarding the importance of the initial asset class weights for the future portfolio performance). Since households' asset allocation is significantly driven by households' socioeconomics and sociodemographics (see, e.g., Guiso and Sodini 2013; Kaustia et al. 2016 and the therein cited literature), this study also focuses on the question whether a subsample of households with certain sociodemographic and socioeconomic characteristics would have benefited more from portfolio rebalancing than other households.

\section{Data and methodology}

The portfolios and household characteristics for the analysis are from the German central bank's (Deutsche Bundesbank) Panel on Household Finances (PHF)-Survey (https ://doi.org/10.12757/phf.01.01.01.stata). ${ }^{5}$ The dataset of the PHF-Survey includes the absolute amount of money that each of the 3565 interviewed households invested per asset class. Like in von Gaudecker (2015) and Oehler and Horn (2019), all households whose portfolio undercuts a net value of 1000 EUR are excluded. Since robo-advisers usually do not offer leveraged investment approaches, all households with a negative amount of liquidity and a positive amount in other assets of the portfolio (e.g., stocks and bonds) are precluded in order to not skew the results by the inclusion of leveraged portfolios. Furthermore, households which invest more than $90 \%$ of their portfolios' net value in the asset class cash(-equivalents) are excluded since the impact of a rebalancing strategy on these households' portfolio performance should be negligible.

These constraints leave 830 households for the analysis. The descriptive statistics of the asset weights in these households' portfolios are presented in Table 1. The asset class articles of great value includes households' investments in real assets such as jewelry, art, antiques, stamps, wine and bullion coins. ${ }^{6}$ The own house or cars as further

\footnotetext{
5 See von Kalckreuth et al. (2012) and Deutsche Bundesbank's homepage (http://www.bundesbank.de/Navigation/EN/Bundesbank/ Research/Panel_on_household_finances/panel_on_household_finan ces.html) for a detailed description of the survey's methodology and the dataset as well as analyses regarding households' balance sheets.

${ }^{6}$ A price index for such luxury goods as in Simson and Spaenjers (2015) is not available for German investors. Therefore, we use a certificate on the Solactive Luxury and Lifestyle Index (Total Return) as benchmark for this asset class. Although the benchmark index is based on stocks of companies that produce and/or sell the luxury goods rather than the prices of the luxury goods themselves, the benchmark index is a best estimate solution and its returns are in line with respective returns reported in Simson and Spaenjers (2015). Furthermore, the respective certificate seems like the most intuitive
}

Table 1 Descriptive statistics of asset weights in households' portfolios

\begin{tabular}{llllll}
\hline & \multicolumn{5}{l}{ Percentage invested in asset classes } \\
\cline { 2 - 6 } & $\begin{array}{l}\text { Cash(- } \\
\text { equiva- } \\
\text { lents) }\end{array}$ & Stocks & Bonds & $\begin{array}{l}\text { Real } \\
\text { estate } \\
\text { funds }\end{array}$ & $\begin{array}{l}\text { Articles of } \\
\text { great value }\end{array}$ \\
\hline Mean & 44.9 & 24.0 & 13.0 & 4.1 & 14.0 \\
20th percentile & 14.8 & 0 & 0 & 0 & 0 \\
Median & 45.5 & 15.1 & 0 & 0 & 0 \\
80th percentile & 74.0 & 46.5 & 26.4 & 0 & 26.3 \\
Sdv. & 27.5 & 27.1 & 21.2 & 12.4 & 23.2 \\
$N$ & 830 & 830 & 830 & 830 & 830 \\
\hline
\end{tabular}

This table displays descriptive statistics of the 830 portfolios that exceed a net value of 1000 EUR and at least $10 \%$ of risky assets. We report mean and median values, the 20th and 80th percentile and the standard deviation (Sdv.) of the portfolio shares that are invested in the asset classes stocks, bonds, cash(-equivalents), real estate funds and articles of great value. Example: The mean value of the percentage invested in the asset class cash(-equivalents) is 44.9 with a standard deviation of 27.5. The 20th percentile is 14.8 , and the median value is $45.5 \%$. Twenty percent of the households invest at least $74 \%$ of their portfolio in the asset class cash(-equivalents) (80th percentile)

very valuable position in households' balance sheets are, however, not included in the asset class articles of great value as these assets factually cannot be rebalanced. On average, the portfolios consist of $45 \%$ cash(-equivalents), $24 \%$ stocks, $13 \%$ bonds, $4 \%$ real estate funds and $14 \%$ articles of great value. However, hardly any household invests in all five assets. Bonds and articles of great value are held by less than half of the households, while less than $19 \%$ of the households invest in real estate funds. One-third of the households does not hold stocks.

The households were surveyed by Deutsche Bundesbank in the period from September 14, 2010, to July 15, 2011. Although the exact date of each interview is not available, the respective quarter of the year in which the survey took place is indicated for each household. For the performance analysis, we assume that all households of one quarter were interviewed on the same day in the middle of the quarter. Households' portfolio performance is estimated with the returns of the exchange traded funds (ETFs) and certificates on exchange traded indices in Table 2 and interest rates (as risk-free returns of the asset class cash(-equivalents)) provided by Deutsche Bundesbank. The employed ETFs have German underlying indices due to German investors' significant home or even local bias (see, e.g., Oehler et al. 2007; Baltzer et al. 2015). The development of these assets

\section{Footnote 6 (continued)}

investment for households that want to avoid illiquid investments but nevertheless want to invest in luxury goods. 
Table 2 Benchmarks of asset classes

\begin{tabular}{|c|c|c|c|c|}
\hline Asset class & Benchmark index & ISIN of ETF & $\begin{array}{l}\text { Annual return } \\
11 / 12 / 2010- \\
5 / 18 / 2015\end{array}$ & $\begin{array}{l}\text { Annual standard deviation } \\
\text { of returns 11/12/2010- } \\
5 / 18 / 2015\end{array}$ \\
\hline Stocks & DAX30 Performance Index & DE0005933931 & .117 & .204 \\
\hline Bonds & Barclays Euro Aggregate Bond Index & DE000A0RM447 & .028 & .034 \\
\hline Real estate funds & $\begin{array}{l}\text { Vontobel REITs Low Volatility Performance } \\
\text { Index }\end{array}$ & DE000VT0RLV8 & .105 & .109 \\
\hline Articles of great value & $\begin{array}{l}\text { Solactive Luxury and Lifestyle Index (Total } \\
\text { Return) }\end{array}$ & DE000DR0NUM1 & .176 & .179 \\
\hline
\end{tabular}

Fig. 1 Development of asset classes in observation period

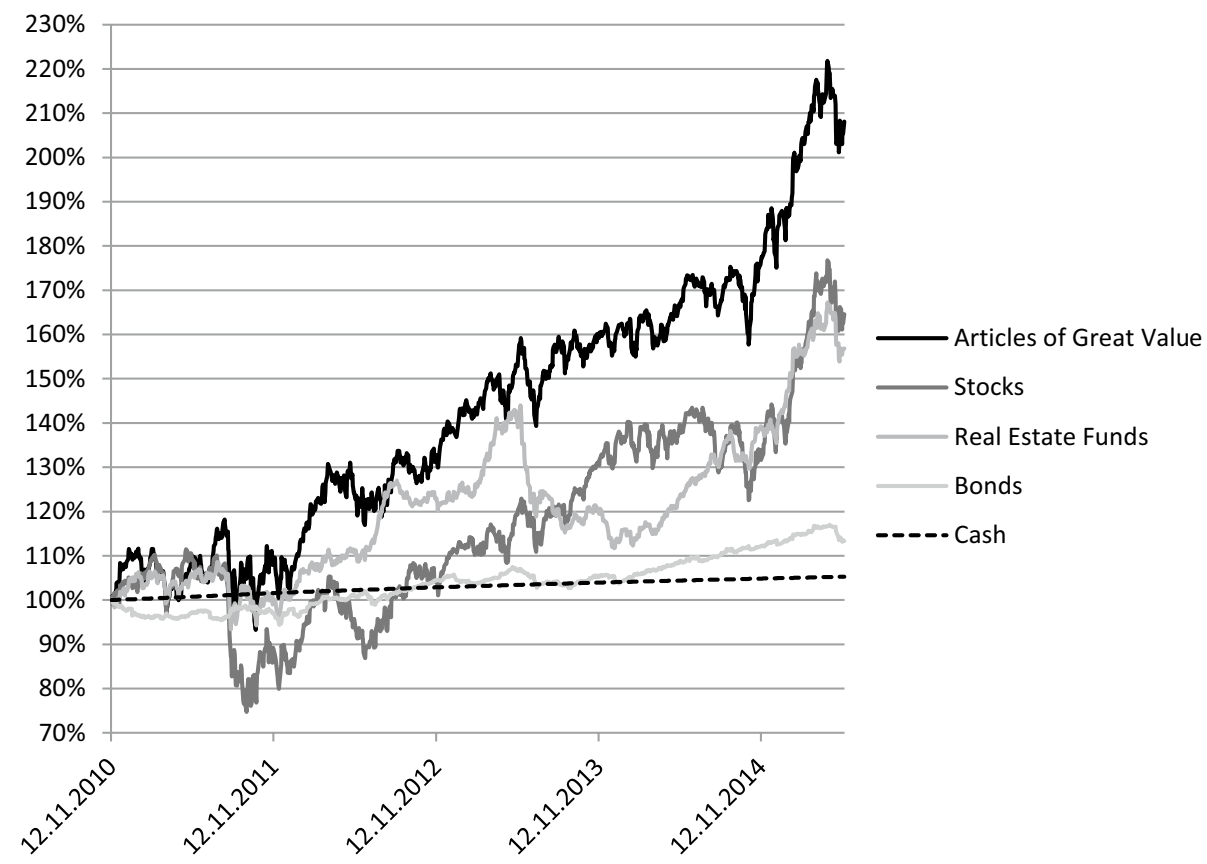

Table 3 Correlation coefficients (Pearson) of assets' returns (November 12, 2010-May 18, 2015)

\begin{tabular}{|c|c|c|c|c|}
\hline & Stocks & Bonds & Real estate funds & $\begin{array}{l}\text { Articles of } \\
\text { great value }\end{array}$ \\
\hline Bonds & $-.07 * *$ & 1 & & \\
\hline Real estate funds & $.40 * * *$ & $.09 * * *$ & 1 & \\
\hline $\begin{array}{l}\text { Articles of great } \\
\text { value }\end{array}$ & $.68 * * *$ & $-.08 * * *$ & $.49 * * *$ & 1 \\
\hline Cash & -.03 & -.03 & -.02 & -.01 \\
\hline
\end{tabular}

The symbols $* * *$ and $* *$ denote statistical significance at the 1 and $5 \%$ level, respectively

is presented in Fig. 1. All five assets earned positive returns in the observation period. The highest annual returns of $17.6 \%$ were achieved in the asset class articles of great value, where prices roughly doubled in the observation period, and the lowest return of about $5 \%$ in total was achieved by the asset class cash(-equivalents). The correlations between the assets' returns are highlighted in Table 3. Returns of bonds and cash(-equivalents) are hardly correlated with each other and the remaining assets' returns in the analyzed time period. Such weak correlations are one key requirement for the success of rebalancing strategies (see, e.g., Pliska and Suzuki 2004; Tokat and Wicas 2007).

The performance analysis' methodology has to fulfill three requirements: first, to measure the performance difference that arises from employing a rebalancing strategy instead of a buy-and-hold strategy; second, to identify the portfolios, or more precisely their asset weights, that benefited from a rebalancing strategy; and third, to derive the characteristics of the households that benefited from rebalancing their portfolio.

For these purposes, households' portfolio performance is computed over a four-year period for (a) a buy-and-hold strategy, (b) periodical rebalancing strategies with rebalancing after (b1) one month or (b2) one year and (c) threshold rebalancing strategies with rebalancing when the worst and 
best performing asset classes' returns in a household's portfolio diverge by (c1) $5 \%$, (c2) $10 \%$ or (c3) $20 \%$ compared to the last rebalancing. ${ }^{7}$ With the rebalancing of the portfolio, all asset weights of a portfolio are set back to their initial values. The portfolio outcomes are computed according to the mean-variance portfolio theory and previous studies (e.g., Hilliard and Hilliard 2018) on the benefits of rebalancing strategies as the mean portfolio return $\mu$, portfolio return's standard deviation $\sigma$ and the portfolio's Sharpe ratio.

However, an unambiguous interpretation of $\mu, \sigma$, and the Sharpe ratio requires normally distributed asset and portfolio returns (see, e.g., Guse and Rudolf 2008). As asset returns are commonly not normally distributed, it seems possible that rebalancing strategies not only change the $\mu$ and $\sigma$ of a portfolio but also the skewness and kurtosis of the portfolio's return distribution. Due to risk averse investors' preference for positively skewed return distributions with low kurtosis (see Scott and Horvath 1980), investors might benefit from rebalancing when the adjustment of the asset weights leads to a more favorable distribution of the portfolio returns. To capture the latter effect, we analyze the change of the adjusted Sharpe ratio through portfolio rebalancing (see Pézier and White 2006). The adjusted Sharpe ratio for the portfolio of household $i\left(\mathrm{ASR}_{i}\right)$ is computed as:

$\mathrm{ASR}_{i}=\mathrm{SR}_{i}\left(1+\left(\frac{\text { Skewness }_{i}}{6}\right) \mathrm{SR}_{i}-\left(\frac{\left[\text { Kurtosis }_{i}-3\right]}{24}\right) \mathrm{SR}_{i}^{2}\right)$

with $\mathrm{SR}_{i}$ as the Sharpe ratio of the portfolio of household $i$.

The adjusted Sharpe ratio incorporates a penalty (gain) factor (the term in parentheses) for negative (positive) skewness and excess (limited) kurtosis. If this factor increases, rebalancing has a favorable effect for risk averse households regarding the skewness (Skewness ${ }_{i}$ ) and kurtosis (Kurtosis ${ }_{i}$ ) of their portfolio's return distribution. ${ }^{8}$ Additional performance measures are not considered since previous studies show that the choice of the performance measure is not critical for the performance evaluation (see, e.g., Eling 2008;

\footnotetext{
7 We also calculated households' portfolio performance for strategies that combine threshold strategies with periodical strategies, e.g., a strategy that either immediately rebalances the portfolio if a 5\% threshold level is exceeded or if the portfolio was not rebalanced in the previous month. However, the outcomes of these strategies (e.g., $5 \%$ threshold plus monthly rebalancing yielded on average an annual $\mu$ of $6.290 \%, \sigma$ of $7.900 \%$ and Sharpe ratio of .7100 ) were not different from the outcomes of the threshold strategies (e.g., 5\% threshold rebalancing yielded on average an annual $\mu$ of $6.285 \%, \sigma$ of $7.905 \%$ and Sharpe ratio of .7088) at statistically significant levels. Therefore, this paper solely focuses on the threshold and periodical strategies to more clearly derive the effects of the separate strategies on households' portfolio outcomes.

${ }^{8}$ Some individual investors might-in dependence of their investment goal-prefer return distributions with negative skewness and excess kurtosis. This, however, should be the minority and those investors seem unlikely to employ robo-advisers for their investments.
}

Dichtl et al. 2016), even when returns are not normally distributed (see Adcock 2012).

We assume that rebalancing strategies do not provide the same benefits for different portfolios with different asset weights. Consequently, linear regression analyses with the asset weights as independent variables are employed to analyze the asset weights' influence on the performance benefits of the rebalancing strategies (measured as increase of the Sharpe ratio and increase of the gain factor of the adjusted Sharpe ratio). The dependent variables of the regression analyses are the change of the Sharpe ratio $\left(\Delta \mathrm{SR}_{i}\right)$ and the change of the gain factor of the adjusted Sharpe ratio of household $i\left(\triangle \mathrm{ASRFactor}_{i}\right)$ resulting from the usage of rebalancing strategies. The respective linear regression models are as follows.

$$
\begin{aligned}
& \Delta \mathrm{SR}_{i}= \beta_{0}+\beta_{1} * \text { Cash }_{i}+\beta_{2} * \text { Stocks }_{i}+\beta_{3} * \text { Bonds }_{i} \\
&+\beta_{4} * \text { Real Estate Funds } \\
&+\beta_{5} * \text { Articles Of Great Value } \\
& i
\end{aligned}
$$

with $\mathrm{Cash}_{i}$ as percentage of portfolio's net value invested in cash(-equivalents);

Stocks ${ }_{i}$ as percentage of portfolio's net value invested in stocks;

Bonds ${ }_{i}$ as percentage of portfolio's net value invested in bonds;

Real Estate Funds ${ }_{i}$ as percentage of portfolio's net value invested in real estate funds;

Articles Of Great Value ${ }_{i}$ as percentage of portfolio's net value invested in articles of great value.

$$
\begin{aligned}
& \Delta A \text { SR Factor } i=\beta_{0}+\beta_{1} * \operatorname{Cash}_{i}+\beta_{2} * \operatorname{Stocks}_{i}+\beta_{3} * \text { Bonds }_{i} \\
& +\beta_{4} * \text { Real Estate Funds } \\
& +\beta_{5} * \text { Articles Of Great Value }{ }_{i}+\varepsilon
\end{aligned}
$$

$\mathrm{Cash}_{i}$ is only mentioned for the sake of completeness. As the five considered asset weights sum up to $100 \%, \mathrm{Cash}_{i}$ is omitted in the regression analyses. Since households' asset allocation is significantly driven by households' characteristics, it seems possible that some households with certain socioeconomics and sociodemographics can expect higher benefits from rebalancing strategies than the remaining households. The following linear regression models are used to analyze this relation and to derive stylized characteristics of the households that benefited from rebalancing their portfolio. The included household characteristics have shown to be the most relevant in previous studies, while other characteristics such as education and financial literacy played a minor role (see Kaustia et al. 2016; Oehler and Horn 2019, 2020).

$$
\begin{aligned}
\Delta \mathrm{SR}_{i}= & \beta_{0}+\beta_{1} * \ln \text { Value } P_{i}+\gamma_{1} * \text { Risk At } t_{i}+\beta_{2} * \text { Age }_{i} \\
& +\beta_{3} * \text { Age }_{i}^{2}+\beta_{4} * \text { Female }_{i}+\beta_{5} * \ln \text { TWealth }_{i} \\
& +\beta_{6} * \ln _{\text {Income }}+\beta_{7} * \text { Child }_{i}+\varepsilon
\end{aligned}
$$


with $\ln$ Value $P_{i}$ as value of household $i$ 's portfolio;

Risk At $t_{i}$ as vector of households' directly queried willingness to take financial risk" with the manifestations "no risk," "average risk," "above average risk" each with a commensurate return where "average risk" is the vector's basis;

Age $_{i}$ as age of the households' financial knowledgeable person (FKP);

Female $_{h}$ as 1 if the household's FKP is female and 0 if the household's FKP is male;

$\ln$ TWealth $_{i}$ as the logarithmized estimate of household's total wealth (sum of financial and real assets net of liabilities);

ln Income $_{i}$ as the logarithmized estimate of household's monthly net income;

Child $_{i}$ as 1 if at least one person of 16 years or younger lives in the household and 0 otherwise.

$$
\begin{aligned}
& \triangle \text { ASR Factor }{ }_{i}=\beta_{0}+\beta_{1} * \ln \text { Value } P_{i}+\gamma_{1} * \text { Risk At } t_{i}+\beta_{2} * \text { Age }_{i} \\
& +\beta_{3} * \text { Age }_{i}^{2}+\beta_{4} * \text { Female }_{i}+\beta_{5} * \text { ln TWealth }_{i} \\
& +\beta_{6} * \ln \text { Income }_{i}+\beta_{7} * \text { Child }_{i}+\varepsilon
\end{aligned}
$$

The mean (median) portfolio value Value $P_{i}$ is 192,141 (74,050) EUR. Most households' willingness to take financial risk (Risk At $t_{i}$ ) is characterized by a high or medium degree of risk aversion. About $35 \%$ of the households are not willing to take any financial risks. Sixty (5)\% of the households would take average (above average) financial risk for a commensurate return. The mean (median) age of the households' FKP $\left(\mathrm{Age}_{i}\right.$ ) is 59 (60) years. A total of 279 of the 830 analyzed households have a female FKP who is mainly responsible for the household's finances. The households in the sample estimate their mean total wealth $\left(\right.$ TWealth $_{i}$ ) with 615,631 (median 350,000) EUR and their mean monthly net income ( Income $_{i}$ ) with 4192 (median 3500) EUR. In $15 \%$ of the households lives at least one child of 16 years or younger.

\section{Results}

\section{Comparison of portfolio performance resulting from buy-and-hold and rebalancing strategies}

The mean $\mu$ and $\sigma$ of households' portfolios when households would have applied a buy-and-hold strategy are compared with the $\mu$ and $\sigma$ when households would have applied a rebalancing strategy in Table 4 . By employing a buy-andhold strategy, households' portfolios would have earned an annual mean $\mu$ of $6.3 \%$ (median $5.7 \%$ ). When households had applied a periodical rebalancing strategy to adjust their

\footnotetext{
9 This item is frequently used in surveys as a proxy for the respondent's risk attitude in financial decisions (see, e.g., Kaustia et al. 2016).
}

portfolio on a monthly or an annual basis, their mean annual $\mu$ would had decreased by .05 or $.15 \%$, respectively. These decreases are statistically significant at the $1 \%$ level although the median return delta is zero. The threshold rebalancing strategies would, on average, lead to 55 (5\%-divergence strategy, which is that the portfolio is rebalanced when the worst and best performing asset classes' returns in a household's portfolio diverge by $5 \%$ compared to the last rebalancing), 15 (10\%-divergence) or 4 (20\%-divergence) portfolio adjustments in the four-year period. While the 5\%-divergence strategy would have earned almost the same returns as the buy-and-hold strategy, the $10 \%$ - and 20\%-divergence strategy would have yielded an annual mean $\mu$ that is .06 to $.07 \%$ lower than the annual mean $\mu$ of the buy-and-hold strategy. The two latter differences are statistically significant at the $1 \%$ level.

However, households might not assess the reduced $\mu$ from rebalancing strategies as negative if the portfolio risk $\sigma$ was simultaneously reduced in a commensurable way. When households had pursued a buy-and-hold strategy, their mean annual $\sigma$ would have been $7.9 \%$ (median $7.0 \%$ ). Except for the $20 \%$-divergence strategy, the application of rebalancing strategies would have decreased the annual mean $\sigma$ by .02 to $.14 \%$ compared to the buy-and-hold strategy. Taken together, rebalancing on average would have led to lower annual $\mu$ combined with a lower mean annual $\sigma$.

The on average simultaneous decrease of portfolio risk and return through rebalancing strategies triggers the question whether these strategies enhance portfolio efficiency. By just comparing the portfolios' $\mu$ and $\sigma$ with and without rebalancing, it is even on an individual portfolio basis hardly possible to answer this question since the majority of the outcomes of the rebalanced portfolios do not dominate (i.e., have a higher $\mu$, while the $\sigma$ stays stable or an at least equal $\mu$ and the $\sigma$ decreases) the outcomes of the buy-and-hold portfolios and vice versa. ${ }^{10}$ Therefore, the analysis focuses on the change of the portfolios' Sharpe ratio caused by portfolio rebalancing and the changes of the adjusted Sharpe ratio due to risk averse investors' preference for positively skewed return distributions with low kurtosis. The respective results are presented in Table 5. The mean Sharpe ratio of households' portfolios would have been 697 (median .690) when households had pursued a buy-and-hold strategy. Using a rebalancing strategy instead reveals no clear effect. The monthly and 5\%-divergence rebalancing strategies on average would have improved the Sharpe ratio by .006 and .012 compared to the buy-and-hold strategy. In contrast, the annual and $20 \%$-divergence strategy would have reduced the Sharpe ratio by .003 and .008 , respectively. Measuring the portfolio performance with the adjusted Sharpe ratio leads to

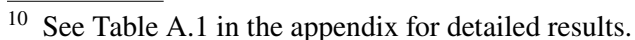


Table 4 Portfolio outcomes of rebalancing strategies compared to buy-and-hold strategy over a 4 year period

\begin{tabular}{|c|c|c|c|c|c|c|c|}
\hline \multirow{2}{*}{\multicolumn{2}{|c|}{$\begin{array}{l}\text { Annual } \mu \text { buy-and- } \\
\text { hold strategy }\end{array}$}} & \multicolumn{6}{|c|}{ Delta annual $\mu$ compared to buy-and-hold strategy } \\
\hline & & & Monthly rebalancing & $\begin{array}{l}\text { Annual } \\
\text { rebalancing }\end{array}$ & $\begin{array}{l}5 \% \text {-divergence } \\
\text { rebalancing }\end{array}$ & $\begin{array}{l}10 \% \text {-divergence } \\
\text { rebalancing }\end{array}$ & $\begin{array}{l}\text { 20\%-divergence } \\
\text { rebalancing }\end{array}$ \\
\hline Mean & .0627 & Mean & $-.0005 * * *$ & $-.0015 * * *$ & .0002 & $-.0006 * * *$ & $-.0007 * * *$ \\
\hline $20 \%$ & .033 & $20 \%$ & -.003 & -.004 & -.003 & -.003 & -.003 \\
\hline Median & .057 & Median & .000 & .000 & .001 & .000 & .000 \\
\hline $80 \%$ & .089 & $80 \%$ & .002 & .000 & .003 & .002 & .002 \\
\hline$\underline{\text { Std. }}$ & .033 & Std. & .003 & .003 & .003 & .003 & .003 \\
\hline \multirow{2}{*}{\multicolumn{2}{|c|}{$\begin{array}{l}\text { Annual } \sigma \text { buy-and- } \\
\text { hold strategy }\end{array}$}} & \multicolumn{6}{|c|}{ Delta annual $\sigma$ compared to buy-and-hold strategy } \\
\hline & & & Monthly rebalancing & $\begin{array}{l}\text { Annual } \\
\text { rebalancing }\end{array}$ & $\begin{array}{l}5 \% \text {-divergence } \\
\text { rebalancing }\end{array}$ & $\begin{array}{l}10 \% \text {-divergence } \\
\text { rebalancing }\end{array}$ & $\begin{array}{l}\text { 20\%-divergence } \\
\text { rebalancing }\end{array}$ \\
\hline Mean & .0792 & Mean & $-.0007 * * *$ & $-.0014 * * *$ & $-.0002 *$ & $-.0002 * * *$ & $.0003 * * *$ \\
\hline $20 \%$ & .031 & $20 \%$ & -.004 & -.003 & -.003 & -.003 & -.002 \\
\hline Median & .070 & Median & .000 & -.001 & .000 & .000 & .001 \\
\hline $80 \%$ & .127 & $80 \%$ & .002 & .000 & .002 & .003 & .003 \\
\hline Std. & .051 & Std. & .003 & .002 & .003 & .003 & .003 \\
\hline
\end{tabular}

We report the mean values $20 \%$ percentiles, median values, $80 \%$ percentiles and standard deviations of the differences of the annual return and annual standard deviation of returns between a buy-and-hold strategy and the outcomes of a rebalancing strategy for the same portfolios. Next to the mean values, we provide the results of parametric t-tests that test whether the mean values differ from 0 at statistically significant levels. The symbols $* * *, * *$ and $*$ denote statistical significance at the 1,5 and $10 \%$ level, respectively. Example: The portfolios achieve a .05\% lower mean return with monthly rebalancing strategies than with a buy-and-hold strategy. The lower mean return is different from zero with a statistical significance at the $1 \%$ level

Table 5 Portfolio outcomes of rebalancing strategies compared to buy-and-hold strategy over a 4 year period

\begin{tabular}{|c|c|c|c|c|c|c|c|}
\hline \multirow{2}{*}{\multicolumn{2}{|c|}{$\begin{array}{l}\text { Sharpe ratio buy-and- } \\
\text { hold strategy }\end{array}$}} & \multicolumn{6}{|c|}{ Delta Sharpe ratio compared to buy-and-hold strategy } \\
\hline & & & Monthly rebalancing & Annual rebalancing & $\begin{array}{l}5 \% \text {-divergence } \\
\text { rebalancing }\end{array}$ & $\begin{array}{l}10 \% \text {-divergence } \\
\text { rebalancing }\end{array}$ & $\begin{array}{l}\text { 20\%-divergence } \\
\text { rebalancing }\end{array}$ \\
\hline Mean & 697 & Mean & $.006^{* * *}$ & $-.003^{* * *}$ & $.012 * * *$ & .001 & $-.008 * * *$ \\
\hline $20 \%$ & .471 & $20 \%$ & -.010 & -.023 & -.004 & -.017 & -.027 \\
\hline Median & 690 & Median & .000 & .000 & .007 & -.001 & -.006 \\
\hline $80 \%$ & .914 & $80 \%$ & .020 & .013 & .028 & .017 & .008 \\
\hline Std. & .235 & Std. & .030 & .031 & .031 & .030 & .028 \\
\hline \multirow{2}{*}{\multicolumn{2}{|c|}{$\begin{array}{l}\text { Adjusted Sharpe ratio } \\
\text { buy-and-hold strategy }\end{array}$}} & \multicolumn{6}{|c|}{ Delta adjusted Sharpe ratio compared to buy-and-hold strategy } \\
\hline & & & Monthly rebalancing & Annual rebalancing & $\begin{array}{l}5 \% \text {-divergence } \\
\text { rebalancing }\end{array}$ & $\begin{array}{l}10 \% \text {-divergence } \\
\text { rebalancing }\end{array}$ & $\begin{array}{l}\text { 20\%-divergence } \\
\text { rebalancing }\end{array}$ \\
\hline Mean & .630 & Mean & $-.009 * * *$ & $-.018 * * *$ & $-.010 * * *$ & $-.017 * * *$ & $-.019 * * *$ \\
\hline $20 \%$ & .453 & $20 \%$ & -.031 & -.048 & -.035 & -.038 & -.044 \\
\hline Median & .626 & Median & -.002 & -.000 & .001 & -.008 & -.009 \\
\hline $80 \%$ & .804 & $80 \%$ & .013 & .012 & .018 & .005 & .005 \\
\hline Std. & .189 & Std. & .189 & .054 & .044 & .038 & .039 \\
\hline
\end{tabular}

We report the mean values, $20 \%$ percentiles, median values, $80 \%$ percentiles and standard deviations of the differences of the Sharpe ratio and adjusted Sharpe ratio between a buy-and-hold strategy and the outcomes of a rebalancing strategy for the same portfolios. Next to the mean values, we provide the results of parametric $t$-tests that test whether the mean values differ from 0 at statistically significant levels. The symbols $* * *, * *$ and $*$ denote statistical significance at the 1, 5 and 10\% level, respectively. Example: The portfolios achieve a .006 higher mean Sharpe ratio with monthly rebalancing strategies than with a buy-and-hold strategy. The higher mean Sharpe ratio is different from zero with a statistical significance at the $1 \%$ level 
Table 6 Influence of households' asset mix on the success of rebalancing strategies measured as increase in Sharpe ratio $\left(\Delta \mathrm{SR}_{i}\right)$ over a 4 year period

\begin{tabular}{|c|c|c|c|c|c|}
\hline & Monthly rebalancing & Annual rebalancing & $\begin{array}{l}\text { 5\%-divergence } \\
\text { rebalancing }\end{array}$ & $\begin{array}{l}\text { 10\%-divergence } \\
\text { rebalancing }\end{array}$ & $\begin{array}{l}\text { 20\%-divergence } \\
\text { rebalancing }\end{array}$ \\
\hline Cash(-equivalents) & Omitted & Omitted & Omitted & Omitted & Omitted \\
\hline Stocks & $\begin{array}{l}.007 \\
(.004)\end{array}$ & $\begin{array}{l}.021 * * * \\
(.004)\end{array}$ & $\begin{array}{l}-.005 \\
(.005)\end{array}$ & $\begin{array}{l}-.001 \\
(.004)\end{array}$ & $\begin{array}{l}.030 * * * \\
(.004)\end{array}$ \\
\hline Bonds & $\begin{array}{l}.017 * * * \\
(.005)\end{array}$ & $\begin{array}{l}.019 * * * \\
(.005)\end{array}$ & $\begin{array}{l}.007 \\
(.005)\end{array}$ & $\begin{array}{l}.016 * * * \\
(.005)\end{array}$ & $\begin{array}{l}.035^{* * *} \\
(.005)\end{array}$ \\
\hline Real estate funds & $\begin{array}{l}.026 * * * \\
(.008)\end{array}$ & $\begin{array}{l}.057 * * * \\
(.008)\end{array}$ & $\begin{array}{l}-.000 \\
(.009)\end{array}$ & $\begin{array}{l}.039 * * * \\
(.009)\end{array}$ & $\begin{array}{l}.060 * * * \\
(.007)\end{array}$ \\
\hline Articles of great value & $\begin{array}{l}-.015^{* * *} \\
(.005)\end{array}$ & $\begin{array}{l}-.026^{* * * *} \\
(.005)\end{array}$ & $\begin{array}{l}-.027 * * * \\
(.005)\end{array}$ & $\begin{array}{l}-.004 \\
(.005)\end{array}$ & $\begin{array}{l}-.005 \\
(.005)\end{array}$ \\
\hline$\beta_{0}$ & $\begin{array}{l}.003 \\
(.002)\end{array}$ & $\begin{array}{l}-.010^{* * * *} \\
(.002)\end{array}$ & $\begin{array}{l}.016^{* * * *} \\
(.002)\end{array}$ & $\begin{array}{l}-.001 \\
(.002)\end{array}$ & $\begin{array}{l}-.022 * * * \\
(.002)\end{array}$ \\
\hline$R^{2}$ & .054 & .174 & .045 & .041 & .190 \\
\hline$R^{2}$ adj. & .049 & .170 & .040 & .036 & .186 \\
\hline$F$-Test & 11.680 & 43.393 & 9.618 & 8.786 & 48.252 \\
\hline $\begin{array}{l}\text { VIF (highest value among all } \\
\text { independent variables) }\end{array}$ & 1.412 & 1.412 & 1.412 & 1.412 & 1.412 \\
\hline
\end{tabular}

We provide regression coefficients, their respective standard errors (in parentheses), $R^{2}$, adjusted $R^{2}, F$-statistics and VIF for the regression analysis using Eq. (1) with the increase of the Sharpe ratio resulting from the usage of rebalancing strategies instead of a buy-and-hold strategy as dependent variable. The symbols $* * *, * *$ and $*$ denote statistical significance at the 1, 5 and $10 \%$ level, respectively. Example: Regressing the increase of the Sharpe ratio of households' portfolios with a monthly rebalancing strategy on the model of Eq. (1) yields a coefficient of the percentage of stocks in the portfolio of .007 with no statistical significance and an adjusted $R^{2}$ of .049

clearer results. The mean (median) adjusted Sharpe ratio of the buy-and-hold strategy is .630. All rebalancing strategies undercut this value by .009 to .019 . The difference between the mean adjusted Sharpe ratio of the buy-and-hold strategy and the mean adjusted Sharpe ratios of the rebalancing strategies is statistically significant at the $1 \%$ level for all rebalancing strategies. This means that employing rebalancing strategies would have led to a less favorable skewness and kurtosis of the return distribution from a risk averse investor's view.

Although the rebalancing strategies, on average, provide a statistically significant different portfolio performance than a buy-and-hold strategy, the economic differences are rather negligible for the households. The findings of this study are therefore similar to those of Tokat and Wicas (2007) who also find relatively small differences in risk and return among the various rebalancing strategies. Since rebalancing, in general, would not have enhanced the (adjusted) Sharpe ratios at a statistically significant level before transaction costs, it is clear that the rebalancing strategies would have had no positive effect after transaction costs. Therefore, we do not provide an analysis with transaction costs at this stage.

\section{The relation between the initial asset allocation and the benefits from portfolio rebalancing}

Since the success of a rebalancing strategy is likely to depend on the initial asset allocation, we perform regression analyses with the assets' portfolio shares as independent variables and the Sharpe ratio increase/decrease caused by rebalancing as dependent variables (see model (1)). ${ }^{11}$ The regression analyses account for interdependencies between the assets' portfolio shares, which helps to isolate the influence of each asset's share on the variation of the Sharpe ratio. The results of the regression analysis are presented in Table 6 . Rebalancing would have led to a stronger increase of the portfolios' Sharpe ratio the higher the initial share of stocks and real estate funds is. The regression analysis derives that this is also the case for a higher share of bonds. In contrast, portfolios would have suffered more strongly from rebalancing when they include a higher percentage of articles of great value. Values of the regression analyses' (adjusted) $R$-squared furthermore show that households' asset mix explains a higher proportion of the rebalancing induced changes of the Sharpe ratios for strategies with lower rebalancing

\footnotetext{
11 See Appendix II for detailed descriptive statistics of portfolios that benefitted and portfolios that suffered from rebalancing.
} 
Table 7 Influence of households' asset mix on the success of rebalancing strategies measured as increase in ASR factor $\left(\triangle\right.$ ASRFactor $\left._{i}\right)$ over a 4 year period

\begin{tabular}{|c|c|c|c|c|c|}
\hline & Monthly rebalancing & Annual rebalancing & $\begin{array}{l}5 \% \text {-divergence } \\
\text { rebalancing }\end{array}$ & $\begin{array}{l}10 \% \text {-divergence } \\
\text { rebalancing }\end{array}$ & $\begin{array}{l}\text { 20\%-divergence } \\
\text { rebalancing }\end{array}$ \\
\hline Cash(-equivalents) & Omitted & Omitted & Omitted & Omitted & Omitted \\
\hline Stocks & $\begin{array}{l}.047 * * * \\
(.003)\end{array}$ & $\begin{array}{l}.068 * * * \\
(.009)\end{array}$ & $\begin{array}{l}.067 * * * \\
(.004)\end{array}$ & $\begin{array}{l}.057 * * * \\
(.004)\end{array}$ & $\begin{array}{l}.039 * * * \\
(.003)\end{array}$ \\
\hline Bonds & $\begin{array}{l}.031 * * * \\
(.004)\end{array}$ & $\begin{array}{l}.052 * * * \\
(.010)\end{array}$ & $\begin{array}{l}.046 * * * \\
(.005)\end{array}$ & $\begin{array}{l}.040 * * * \\
(.005)\end{array}$ & $\begin{array}{l}.029 * * * \\
(.003)\end{array}$ \\
\hline Real estate funds & $\begin{array}{l}.033 * * * \\
(.007)\end{array}$ & $\begin{array}{l}.051 * * * \\
(.017)\end{array}$ & $\begin{array}{l}.040 * * * \\
(.009)\end{array}$ & $\begin{array}{l}.040 * * * \\
(.008)\end{array}$ & $\begin{array}{l}.029 * * * \\
(.006)\end{array}$ \\
\hline Articles of great value & $\begin{array}{l}-.003 \\
(.004)\end{array}$ & $\begin{array}{l}.024 * * \\
(.010)\end{array}$ & $\begin{array}{l}-.006 \\
(.005)\end{array}$ & $\begin{array}{l}.000 \\
(.005)\end{array}$ & $\begin{array}{l}-.003 \\
(.003)\end{array}$ \\
\hline$\beta_{0,}$ & $\begin{array}{l}-.032 * * * \\
(.002)\end{array}$ & $\begin{array}{l}-.046 * * * \\
(.004)\end{array}$ & $\begin{array}{l}-.046 * * * \\
(.002)\end{array}$ & $\begin{array}{l}-.041 * * * \\
(.002)\end{array}$ & $\begin{array}{l}-.027 * * * \\
(.001)\end{array}$ \\
\hline$R^{2}$ & .256 & .086 & .310 & .274 & .275 \\
\hline$R^{2}$ adj. & .252 & .082 & .307 & .271 & .271 \\
\hline$F$-Test & 70.976 & 19.496 & 92.768 & 77.961 & 78.232 \\
\hline $\begin{array}{l}\text { VIF (highest value among all } \\
\text { independent variables) }\end{array}$ & 1.412 & 1.412 & 1.412 & 1.412 & 1.412 \\
\hline
\end{tabular}

We provide regression coefficients, their respective standard errors (in parentheses), $R^{2}$, adjusted $R^{2}, F$-statistics and VIF for the regression analysis using Eq. (2) with the increase of the Adjusted Sharpe ratio factor (ASR factor) resulting from the usage of rebalancing strategies instead of a buy-and-hold strategy as dependent variable. The symbols ***,** and * denote statistical significance at the 1,5 and $10 \%$ level, respectively. Example: Regressing the increase of the ASR factor of households' portfolios with a monthly rebalancing strategy on the model of Eq. (2) yields a coefficient of the percentage of stocks in the portfolio of .047 with a statistical significance at the $1 \%$ level and an adjusted $R^{2}$ of .252

frequency, i.e., annual and 20\%-divergence rebalancing. Since these two strategies are the only ones with a statistically significant negative impact on the household portfolios' Sharpe ratios, the regression analyses seem to provide more explanatory power regarding the asset mixes that suffer from rebalancing than the asset mixes that gain from rebalancing.

Using model (2) we furthermore regress the influence of the assets shares on the change of the portfolios' ASR factor caused by rebalancing. The respective results in Table 7 show that rebalancing would have led to a higher ASR factor, i.e., a more favorable return distribution for risk averse investors, for portfolios with higher percentages of stocks, bonds and real estate funds. The share of articles of great value hardly has a statistically significant influence on the change of the ASR factor. Compared to the regression analyses regarding the remaining four strategies, the regression analysis for the annual rebalancing shows an at least 17 percentage points lower adjusted $R$-squared of .082 . The reasons for this effect are, however, hardly assessable with the data of this study and remain subject for further research.

Taken together, the results reveal that households whose portfolio largely consists of stocks, bonds and real estate funds could have increased their portfolio performance through rebalancing on the one hand. On the other hand, households that initially invested a higher percentage of their portfolio in articles of great value would have suffered from rebalancing.

\section{The relation between households' characteristics and the benefits from portfolio rebalancing}

So far, the findings have shown that households' asset allocation is significantly responsible for households' profits and drawbacks from rebalancing. However, households' asset allocation is driven by households' socioeconomics and sociodemographics. ${ }^{12}$ Therefore, it seems possible that the benefits of rebalancing might also depend on these household characteristics. Linear regression analyses using model (3) are employed to investigate whether such a link between the households' characteristics and households' Sharpe ratio gains/losses exists. The respective results are presented in Table 8. However, the adjusted $R^{2} \mathrm{~s}$ of the regression analyses do not exceed $2.8 \%$ and therefore reveal that a possible relation between households' characteristics and the benefits from rebalancing is only very weak or even not existent. The only household characteristic with a statistically significant influence at the $1 \%$ level is the value of households' portfolio. Households with a more valuable portfolio could have slightly increased their Sharpe ratio if they had used a periodical rebalancing strategy. But the regression coefficients are so small that an economically significant effect can hardly be expected.

\footnotetext{
$\overline{12}$ See Appendix III for detailed results.
} 
Table 8 Influence of households' characteristics on the success of rebalancing strategies measured as increase in Sharpe ratio $\left(\triangle \mathrm{SR}_{i}\right)$ over a 4 year period

\begin{tabular}{|c|c|c|c|c|c|}
\hline & $\begin{array}{l}\text { Monthly } \\
\text { rebalancing }\end{array}$ & $\begin{array}{l}\text { Annual } \\
\text { rebalancing }\end{array}$ & $\begin{array}{l}\text { 5\%-divergence } \\
\text { rebalancing }\end{array}$ & $\begin{array}{l}\text { 10\%-divergence } \\
\text { rebalancing }\end{array}$ & $\begin{array}{l}\text { 20\%-divergence } \\
\text { rebalancing }\end{array}$ \\
\hline $\ln$ Value $P_{i}$ & $\begin{array}{l}.002 * * \\
(.001)\end{array}$ & $\begin{array}{l}.003 * * * \\
(.001)\end{array}$ & $\begin{array}{l}.002 \\
(.001)\end{array}$ & $\begin{array}{l}.001 \\
(.001)\end{array}$ & $\begin{array}{l}.003 * * * \\
(.001)\end{array}$ \\
\hline Above Average Risk ${ }_{i}$ & $\begin{array}{l}-.002 \\
(.005)\end{array}$ & $\begin{array}{l}.000 \\
(.005)\end{array}$ & $\begin{array}{l}-.006 \\
(.005)\end{array}$ & $\begin{array}{l}-.003 \\
(.005)\end{array}$ & $\begin{array}{l}.000 \\
(.004)\end{array}$ \\
\hline No Risk ${ }_{i}$ & $\begin{array}{l}-.001 \\
(.002)\end{array}$ & $\begin{array}{l}-.005^{* *} \\
(.002)\end{array}$ & $\begin{array}{l}-.005^{*} \\
(.002)\end{array}$ & $\begin{array}{l}-.001 \\
(.002)\end{array}$ & $\begin{array}{l}-.006 \\
(.002)\end{array}$ \\
\hline $\mathrm{Age}_{i}$ & $\begin{array}{l}-.001 \\
(.000)\end{array}$ & $\begin{array}{l}.000 \\
(.000)\end{array}$ & $\begin{array}{l}.000 \\
(.000)\end{array}$ & $\begin{array}{l}.000 \\
(.000)\end{array}$ & $\begin{array}{l}.000 \\
(.000)\end{array}$ \\
\hline $\mathrm{Age}_{i}^{2}$ & $\begin{array}{l}.000 \\
(.000)\end{array}$ & $\begin{array}{l}-.000 \\
(.000)\end{array}$ & $\begin{array}{l}.000 \\
(.000)\end{array}$ & $\begin{array}{l}.000 \\
(.000)\end{array}$ & $\begin{array}{l}.000 \\
(.000)\end{array}$ \\
\hline Female $_{i}$ & $\begin{array}{l}-.003 \\
(.002)\end{array}$ & $\begin{array}{l}-.003 \\
(.002)\end{array}$ & $\begin{array}{l}-.002 \\
(.002)\end{array}$ & $\begin{array}{l}-.002 \\
(.002)\end{array}$ & $\begin{array}{l}-.004^{*} \\
(.002)\end{array}$ \\
\hline $\ln _{\text {TWealth }}$ & $\begin{array}{l}.001 \\
(.001)\end{array}$ & $\begin{array}{l}.001 \\
(.001)\end{array}$ & $\begin{array}{l}-.000 \\
(.001)\end{array}$ & $\begin{array}{l}.000 \\
(.001)\end{array}$ & $\begin{array}{l}.000 \\
(.001)\end{array}$ \\
\hline $\ln$ Income $_{i}$ & $\begin{array}{l}-.001 \\
(.002)\end{array}$ & $\begin{array}{l}-.003 \\
(.002)\end{array}$ & $\begin{array}{l}.001 \\
(.002)\end{array}$ & $\begin{array}{l}.000 \\
(.002)\end{array}$ & $\begin{array}{l}-.002 \\
(.002)\end{array}$ \\
\hline Child $_{i}$ & $\begin{array}{l}-.002 \\
(.003)\end{array}$ & $\begin{array}{l}-.001 \\
(.003)\end{array}$ & $\begin{array}{l}.000 \\
(.003)\end{array}$ & $\begin{array}{l}-.003 \\
(.003)\end{array}$ & $\begin{array}{l}.002 \\
(.003)\end{array}$ \\
\hline$\beta_{0}$ & $\begin{array}{l}-.001 \\
(.018)\end{array}$ & $\begin{array}{l}-.025 \\
(.019)\end{array}$ & $\begin{array}{l}.007 \\
(.019)\end{array}$ & $\begin{array}{l}-.004 \\
(.019)\end{array}$ & $\begin{array}{l}-.011 \\
(.017)\end{array}$ \\
\hline$R^{2}$ & .018 & .036 & .021 & .007 & .038 \\
\hline$R^{2}$ adj. & .007 & .025 & .010 & -.004 & .028 \\
\hline$F$-Test & 1.673 & 3.361 & 1.921 & .661 & 3.623 \\
\hline
\end{tabular}

We provide regression coefficients, their respective standard errors (in parentheses), $R^{2}$, adjusted $R^{2}$, and $F$-statistics for the regression analysis using Eq. (3) with the increase of the Sharpe ratio resulting from the usage of rebalancing strategies instead of a buy-and-hold strategy as dependent variable. The symbols ***, $* *$ and $*$ denote statistical significance at the 1,5 and $10 \%$ level, respectively. Example: Regressing the increase of the Sharpe ratio of households' portfolios with a monthly rebalancing strategy on the model of Eq. (3) yields a coefficient of household's logarithmized portfolio value (ln Value $P_{i}$ ) of .002 with a statistical significance at the $5 \%$ level and an adjusted $R^{2}$ of .007
We analyze whether households' characteristics are related to the effect of rebalancing on their portfolios' return distribution, i.e., their ASR factor, by employing model (4) in a linear regression analysis. The results of the regression analysis in Table 9 show that only two household characteristics have a statistically significant influence on the changes of the ASR factor caused by rebalancing, namely the value of households' portfolio and households' willingness to take financial risk. The higher households' portfolio value the higher is their chance that the ASR factor of their portfolio would have risen by employing rebalancing strategies. Households that state to not be willing to take financial risks were less likely to increase their ASR factor by the application of rebalancing strategies. The adjusted $R^{2} \mathrm{~s}$ of the regression analysis show that households' characteristics rather have predictive power regarding the change of the ASR factor than regarding the change of the Sharpe ratio that is induced by the usage of rebalancing strategies.

Nevertheless, it is hardly tenable to state that one could predict the benefits of portfolio rebalancing just by knowing a household's socioeconomics and sociodemographics or, in turn, that a subsample of households with certain socioeconomics and sociodemographics benefits/suffers most from rebalancing strategies. In combination with the previous results regarding the average impact of rebalancing on households' portfolio performance, we conclude that the application of rebalancing strategies would neither have led to a significant positive performance effect nor to a redistribution of wealth between the considered sociodemographic or socioeconomic subgroups in the analyzed sample and observation period.

\section{Robustness checks}

Rebalancing constitutes a dynamic trading strategy. Consequently, the performance of these strategies is highly path dependent (see, e.g., Dichtl et al. 2016). Therefore, the results may be influenced by specific characteristics of the assets' development in the observation period. Since data of the PHF-Survey were collected over an 11-month period, we can partially control for path dependence by using different starting points for the performance analysis. For this purpose, the dataset is subdivided accordingly to the 
Table 9 Influence of households' characteristics on the success of rebalancing strategies measured as increase in ASR factor $\left(\triangle \mathrm{ASRFactor}_{i}\right)$ over a 4 year period

\begin{tabular}{llllll}
\hline & $\begin{array}{l}\text { Monthly } \\
\text { rebalancing }\end{array}$ & $\begin{array}{l}\text { Annual } \\
\text { rebalancing }\end{array}$ & $\begin{array}{l}\text { 5\%-divergence } \\
\text { rebalancing }\end{array}$ & $\begin{array}{l}10 \% \text {-divergence } \\
\text { rebalancing }\end{array}$ & $\begin{array}{l}20 \% \text {-divergence } \\
\text { rebalancing }\end{array}$ \\
\hline ln Value $P_{i}$ & $.002 * *$ & .001 & $.003 * *$ & .003 & $.002 * * *$ \\
& $(.001)$ & $(.002)$ & $(.001)$ & $(.001)$ & $(.001)$ \\
Above Average Risk & .005 & .012 & .008 & .007 & .004 \\
& $(.004)$ & $(.010)$ & $(.006)$ & $(.005)$ & $(.003)$ \\
No Risk $_{i}$ & $-.009 * * *$ & -.005 & $-.012^{* * *}$ & $-.010^{* * *}$ & $-.007 * * *$ \\
& $(.002)$ & $(.005)$ & $(.003)$ & $(.002)$ & $(.002)$ \\
Age $_{i}$ & .000 & -.001 & .000 & .000 & .000 \\
& $(.000)$ & $(.001)$ & $(.001)$ & $(.000)$ & $(.000)$ \\
Age $_{i}^{2}$ & -.000 & .000 & -.000 & -.000 & -.000 \\
Female $_{i}$ & $(.000)$ & $(.000)$ & $(.000)$ & $(.000)$ & $(.000)$ \\
& -.002 & -.002 & -.003 & -.002 & -.001 \\
$\ln$ TWealth $_{i}$ & $(.002)$ & $(.004)$ & $(.003)$ & $(.002)$ & $(.002)$ \\
& .000 & .001 & .000 & .000 & .000 \\
$\ln$ Income $_{i}$ & $(.001)$ & $(.002)$ & $(.001)$ & $(.001)$ & $(.001)$ \\
& -.001 & .004 & -.001 & .000 & -.001 \\
Child $_{i}$ & $(.002)$ & $(.004)$ & $(.003)$ & $(.002)$ & $(.002)$ \\
$\beta_{0 i}$ & .003 & -.001 & .005 & .001 & .002 \\
$R^{2}$ & $(.003)$ & $(.007)$ & $(.004)$ & $(.003)$ & $(.002)$ \\
$R^{2}$ adj. $_{F-\text { Test }}$ & -.037 & -.057 & $-.050^{* *}$ & $-.048^{* *}$ & $-.041^{* * *}$ \\
\hline & $(.016)$ & $(.037)$ & $(.021)$ & $(.019)$ & $(.013)$ \\
& .055 & .011 & .066 & .059 & .071 \\
& .045 & .000 & .056 & .049 & .060 \\
& 5.314 & .996 & 6.435 & 5.724 & 3.895 \\
\hline
\end{tabular}

We provide regression coefficients, their respective standard errors (in parentheses), $R^{2}$, adjusted $R^{2}$, and $F$-statistics for the regression analysis using Eq. (4) with the increase of the Adjusted Sharpe ratio factor (ASR factor) resulting from the usage of rebalancing strategies instead of a buy-and-hold strategy as dependent variable. The symbols $* * *, * *$ and $*$ denote statistical significance at the 1,5 and $10 \%$ level, respectively. Example: Regressing the increase of the ASR factor of households' portfolios with a monthly rebalancing strategy on the model of Eq. (4) yields a coefficient of household's logarithmized portfolio value (ln Value $P_{i}$ ) of .002 with a statistical significance at the $5 \%$ level and an adjusted $R^{2}$ of .045 quarter when households were interviewed and the analysis is repeated for each subsample. ${ }^{13}$ This method, furthermore, allows checking whether the previous results for the full sample are driven by some households that were interviewed in a specific quarter. Although the subsamples' results show some discrepancies (e.g., a higher percentage of households, which were interviewed in the fourth quarter of 2010, would have benefited from rebalancing than in the other two subsamples), in none of the subsamples, rebalancing strategies would have led to an economically significant positive or negative performance shift. In addition, again no subsample of households that profits or suffers significantly more from rebalancing than other households can be identified.

To the best of our knowledge, this study is the first that includes the asset classes real estate funds and articles of great value in a rebalancing strategy. Since robo-advisers commonly do not provide strategies with these assets and, furthermore, these two asset classes outperform stocks in some periods of the observation period, we focus on the role of these two assets. More specifically, the focus lies on the subsample of households that do not invest in these assets to see how much the results depend on the development of the asset classes real estate funds and articles of great value. The Sharpe ratio gains and adjusted Sharpe ratio gains induced by rebalancing strategies in portfolios without investments in real estate funds and articles of great value are presented in Table 10. Compared to the full sample, the portfolios in this subsample would have benefited slightly more from rebalancing. However, the Sharpe ratio gains are hardly economically significant although they are statistically significant for some strategies. This means that the overall results are not primarily driven by the performance of the real estate funds and articles of great value benchmarks but, instead, also hold for households not investing in these asset classes. 
Table 10 Portfolio outcomes of rebalancing strategies compared to buy-and-hold strategy over a 4-year period (only portfolios without investments in real estate funds and articles of great value, $N=347$ )

\begin{tabular}{|c|c|c|c|c|c|c|c|}
\hline \multicolumn{2}{|c|}{$\begin{array}{l}\text { Outcome buy-and-hold } \\
\text { strategy }\end{array}$} & & $\begin{array}{l}\text { Monthly } \\
\text { rebalancing }\end{array}$ & $\begin{array}{l}\text { Annual } \\
\text { rebalancing }\end{array}$ & $\begin{array}{l}5 \% \text {-divergence } \\
\text { rebalancing }\end{array}$ & $\begin{array}{l}10 \% \text {-divergence } \\
\text { rebalancing }\end{array}$ & $\begin{array}{l}\text { 20\%-divergence } \\
\text { rebalancing }\end{array}$ \\
\hline \multicolumn{2}{|c|}{ Sharpe ratio } & \multicolumn{6}{|c|}{ Delta Sharpe ratio compared to buy-and-hold strategy } \\
\hline Mean & .549 & Mean & $.011 * * *$ & $.007 * * *$ & $.018 * * *$ & .001 & -.002 \\
\hline $20 \%$ & .400 & $20 \%$ & -.001 & .000 & .000 & -.014 & -.027 \\
\hline Median & .612 & Median & .002 & .004 & .011 & .000 & -.015 \\
\hline $80 \%$ & .680 & $80 \%$ & .024 & .015 & .033 & .008 & .000 \\
\hline Std. & .196 & Std. & .034 & .030 & .033 & .033 & .005 \\
\hline \multicolumn{2}{|c|}{ Adjusted Sharpe ratio } & \multicolumn{6}{|c|}{ Delta adjusted Sharpe ratio compared to buy-and-hold strategy } \\
\hline Mean & .490 & Mean & $.008 * * *$ & $.003 * *$ & $.015 * * *$ & $-.002 *$ & $-.003 * * *$ \\
\hline $20 \%$ & .396 & $20 \%$ & -.004 & -.000 & .001 & -.018 & -.019 \\
\hline Median & .495 & Median & .002 & .004 & .009 & -.002 & -.001 \\
\hline $80 \%$ & .563 & $80 \%$ & .019 & .015 & .029 & .010 & .008 \\
\hline Std. & .122 & Std. & .023 & .028 & .022 & .024 & .019 \\
\hline
\end{tabular}

We report the mean values, $20 \%$ percentiles, median values, $80 \%$ percentiles and standard deviations of the differences of the Sharpe ratio and adjusted Sharpe ratio between a buy-and-hold strategy and the outcomes of a rebalancing strategy for the same portfolios. Next to the mean values, we provide the results of parametric $t$ tests that test whether the mean values differ from 0 at statistically significant levels. The symbols $* * *$, ** and * denote statistical significance at the 1,5 and $10 \%$ level, respectively. Example: The portfolios in our dataset achieve a .011 higher mean Sharpe ratio with monthly rebalancing strategies than with a buy-and-hold strategy. The higher mean Sharpe ratio is different from zero with a statistical significance at the $1 \%$ level

\section{Discussion and conclusions}

The empirical analysis regarding a hypothetical robo-advisor that rebalances households' investments in the asset classes stocks, bonds, real estate funds, articles of great value and cash(-equivalents) shows that the analyzed German households, on average, hardly would have benefited from such an automated rebalancing service compared to a buy-and-hold strategy with ETFs in the period from September 2010 to July 2015.

Although transaction costs and management fees may play a crucial role for the success of a rebalancing service (see, e.g., Almadi et al. 2014), they are not considered in the previous analyses as the rebalancing strategies would, on average, not have enhanced households' investment performance even without paying for the service. In an unpublished part of the analysis, we find that none of the households could improve its portfolio performance if annual fees exceed $.4 \%$ of the portfolio value. But we abstain from taking such a threshold at face value, because, as one limitation of the results, asset markets were almost throughout in a bullish phase during the observation period. These market conditions are on principal more favorable for a buy-and-hold strategy (see, e.g., Perold and Sharpe 1988), because if markets are that trendy, there is hardly a chance for a rebalancing strategy to buy past loser assets that might reverse in the future. Instead assets that continue to go up are previously sold due to their past returns. Rebalancing strategies should perform better in times of more volatile asset markets which is why this study's results may underestimate the theoretically achievable benefits of rebalancing strategies. Nevertheless, it should also be considered that all the included asset classes showed on average significant positive returns during the last 120 years (see, e.g., Simson and Spaenjers 2015). Therefore, the analyzed period of time shows a rather typical price pattern. Furthermore, we use different starting points for the performance analyses covering four years. Hence, our analysis should be by and large representative. The only exception is severe market crashes. However, these price developments are usually also very trendy. It seems intuitively clear that rebalancing strategies would underperform a buy-and-hold strategy also in times of crashes since assets that continue to fall are bought due to their past declined prices. Therefore, times in which rebalancing strategies outperform a buyand-hold strategy appear to be scarce.

Hence, the findings of this study clarify that automated rebalancing is not a silver bullet to boost portfolio efficiency. In combination with the findings of Jacobs et al. (2014), who find that smaller shifts in portfolios' asset weights do not hamper portfolio efficiency as long as the portfolio is not tilted extremely towards one asset, our results support the implication of Tokat and Wicas (2007) that reasonable (e.g., yearly) monitoring frequencies and allocation thresholds are sufficient to control households' portfolio risk. The findings 
of this study indicate that households which already invest in different asset classes with ETFs would not have benefited from rebalancing services. Instead, the charged management fees would have harmed these households' investment performance. The latter effect is comparable to paying high fees for active fund management which fails to outperform the benchmark. These findings indicate that the rebalancing services in the current form are probably no sustainable business model as the benefits for investors are too limited. An implication for robo-advisers would be to provide better services that do not only channel the money of their clients into exchange traded funds that are rebalanced subsequently. Instead, roboadvisers should explore households' individual financial situation more thoroughly by checking the entire preexisting portfolio (including, e.g., insurances and retirement savings) and thereafter focus on rebalancing along clients' life cycle, i.e., decreasing portfolio risk when large expenses are in the offing (e.g., buying residential property, financing education of children) or increasing portfolio risk when affordable.

Due to the rebalancing strategies' statistically significant impact on the ASR factor, i.e., the portfolio returns' skewness and kurtosis, it seems a promising path for further research to elaborate rebalancing strategies that also consider the portfolio returns' skewness and kurtosis instead of solely focusing on the mean return and the returns' standard deviation.

Funding Open Access funding provided by Projekt DEAL.

Open Access This article is licensed under a Creative Commons Attribution 4.0 International License, which permits use, sharing, adaptation, distribution and reproduction in any medium or format, as long as you give appropriate credit to the original author(s) and the source, provide a link to the Creative Commons licence, and indicate if changes were made. The images or other third party material in this article are included in the article's Creative Commons licence, unless indicated otherwise in a credit line to the material. If material is not included in the article's Creative Commons licence and your intended use is not permitted by statutory regulation or exceeds the permitted use, you will need to obtain permission directly from the copyright holder. To view a copy of this licence, visit http://creativecommons.org/licenses/by/4.0/.

\section{References}

Adcock, Christopher J. 2012. Conditions Under Which Portfolio Performance Measures Are Monotonic Functions of the Sharpe Ratio. Working paper. University of Sheffield, Sheffield, Management School.

Almadi, Himanshu, David E. Rapach, and Anil Suri. 2014. Return predictability and dynamic asset allocation: How often should investors rebalance? Journal of Portfolio Management 40 (4): 16-27.

Ang, Andrew. 2014. Asset Management: A Systematic Approach to Factor Investing (Financial Management Association Survey and Synthesis Series). Oxford: Oxford University Press.
Annaert, Jan, Marc J.K. De Ceuster, and Wim Van Hyfte. 2005. The value of asset allocation advice: Evidence from The Economist's quarterly portfolio poll. Journal of Banking \& Finance 29 (3): 661-680. https://doi.org/10.1016/j.jbankfin.2004.05.023.

Arrow, Kenneth J. 1971. Essays in the Theory of Risk-Bearing. Amsterdam: North-Holland.

Asness, Clifford S., Tobias J. Moskowitz, and Lasse Heje Pedersen. 2013. Value and Momentum Everywhere. Journal of Finance 58 (3): 929-985.

Badarinza, Christian, John Y. Campbell, and Tarun Ramadorai. 2016. International Comparative Household Finance. NBER: Working Paper 22066. https://www.nber.org/papers/w22066. Accessed 12 May 2019.

Baltzer, Markus, Oscar Stolper, and Andreas Walter. 2015. Home-field advantage or a matter of ambiguity aversion? Local bias among German individual investors. European Journal of Finance 21 (9): 734-754. https://doi.org/10.1080/1351847X.2013.877514.

Barber, Brad M., Yi-Tsung Lee, Yu-Jane Lui, and Terrance Odean. 2009. Just How Much Do Individual Investors Lose by Trading? Review of Financial Studies 22 (2): 609-632. https://doi. org/10.1093/rfs/hhn046.

Bonaparte, Yosef and Russell Cooper. 2009. Costly Portfolio Adjustment. NBER: Working Paper 15227, https://www.nber.org/paper s/w15227.ack. Accessed 12 May 2019.

Bouchey, Paul, Vassilii Nemtchinov, Alex Paulsen, and David M. Stein. 2012. Volatility Harvesting: Why Does Diversifying and Rebalancing Create Portfolio Growth? Journal of Wealth Management 15 (2): 26-35.

Brinson, Gary P., L. Randolph Hood, and Gilbert L. Beebower. 1986. Determinants of Portfolio Performance. Financial Analysts Journal 42 (4): 39-44.

Brinson, Gary P., L. Randolph Hood, and Gilbert L. Beebower. 1995. Determinants of Portfolio Performance. Financial Analysts Journal 51 (1): 133-138. https://doi.org/10.2469/faj.v51.n1.1869.

Brinson, Gary P., Brian D. Singer, and Gilbert L. Beebower. 1991. Determinants of Portfolio Performance II: An Update. Financial Analysts Journal 47 (3): 40-48. https://doi.org/10.2469/faj.v47. n3.40.

Brunnermeier, Markus K., and Stefan Nagel. 2008. Do Wealth Fluctuations Generate Time-Varying Risk Aversion? Micro-Evidence on Individuals' Asset Allocation. American Economic Review 98 (3): 713-736.

Calvet, Laurent E., and Paolo Sodini. 2014. Twin Picks: Disentangling the Determinants of Risk-Taking in Household Portfolios. Journal of Finance 69 (2): 867-906.

Cuthbertson, Keith, Simon Hayley, Nick Motson, and Dirk Nitzsche. 2015. What Does Rebalancing Really Achieve? International Journal of Finance \& Economics 21 (3): 224-240.

Das, Sanjiv, Harry Markowitz, Jonathan Scheid, and Meir Statman. 2010. Portfolio Optimization with Mental Accounts. Journal of Financial and Quantitative Analysis 45 (2): 311-334.

Dayanandan, Ajit, and Minh Lam. 2015. Portfolio Rebalancing - Hype or Hope? Journal of Business Inquiry 14 (2): 79-92.

DeMiguel, Victor, Morenzo Garlappi, and Raman Uppal. 2009. Optimal versus Naive Diversification: How Inefficient Is the 1/N Portfolio Strategy? Review of Financial Studies 22 (5): 1915-1953. https://doi.org/10.1093/rfs/hhm075.

Dichtl, Hubert, Wolfgang Drobetz, and Martin Wambach. 2016. Testing Rebalancing Strategies for Stock-Bond Portfolios Across Different Asset Allocations. Applied Economics 48 (9): 772-788. https://doi.org/10.1080/00036846.2015.1088139.

Donohue, Christopher, and Kenneth Yip. 2003. Optimal Portfolio Rebalancing with Transaction Costs. Journal of Portfolio Management 29 (4): 49-63. https://doi.org/10.3905/jpm.2003.319894.

Duchin, Ran, and Haim Levy. 2009. Markowitz Versus the Talmudic Portfolio Diversification Strategies. Journal of 
Portfolio Management 35 (2): 71-74. https://doi.org/10.3905/ JPM.2009.35.2.071.

Eling, Martin. 2008. Does the Measure Matter in the Mutual Fund Industry? Financial Analyst Journal 64 (3): 54-66.

Ferri, Rick. 2015. On Robos and Humans. Journal of Financial Planning 28 (6): 30.

Foerster, Stephen, Juhani T. Linnainmaa, Brian T. Melter, and Alessandro Previtero. 2017. Retail Financial Advice: Does One Size Fit All? Journal of Finance 72 (4): 1441-1482.

Gennaioli, Nicola, Andrei Shleifer, and Robert Vishny. 2015. Money doctors. Journal of Finance 70 (1): 91-114. https://doi.org/10.1111/jofi.12188.

Goetzmann, William N., and Alok Kumar. 2008. Equity Portfolio Diversification. Review of Finance 12 (3): 433-463. https://doi.org/10.1093/ rof/rfn005.

Guiso, Luigi, Paola Sapienza, and Luigi Zingales. 2008. Trusting the stock market. Journal of Finance 63 (6): 2557-2600.

Guiso, Luigi, and Paolo Sodini. 2013. Household Finance: An Emerging Field. In Handbook of the Economics of Finance, ed. George M. Constantinides, Milton Harris, and Renè M. Stulz, 1397-1532. Amsterdam: Elsevier Science.

Guse, Frank, and Markus Rudolf. 2008. Schiefe in der Portfolioselektion. Credit and Capital Markets 41 (2): 197-216. https://doi. org/10.3790/kuk.41.2.197.

Harjoto, Maretno A., and Frank J. Jones. 2006. Rebalancing Strategy for Stocks and Bonds Asset Allocation. Journal of Wealth Management 9 (1): 37-44. https://doi.org/10.3905/jwm.2006.628682.

Hilliard, Jimmy E., and Jitka Hilliard. 2018. Rebalancing versus buy and hold: theory, simulation and empirical analysis. Review of Quantitative Finance and Accounting 50 (1): 1-32.

Hood, Randolph L. 2005. Determinants of Portfolio Performance-20 Years Later. Financial Analysts Journal 62 (1): 6-8. https://doi. org/10.2469/faj.v61.n5.2750.

Ibbotson, Roger G., and Paul D. Kaplan. 2000. Does Asset Allocation Policy Explain 40, 90, or 100 Percent of Performance? Financial Analysts Journal 56 (1): 26-33.

Jacobs, Heiko, Sebastian Müller, and Martin Weber. 2014. How should individual investors diversify? An empirical evaluation of alternative asset allocation policies. Journal of Financial Markets 19: 62-85. https://doi.org/10.1016/j.finmar.2013.07.004.

Kaustia, Markku, Andrew Conlin, and Niilo Luotonen. 2016. What drives the heterogeneity in portfolio choice? The role of institutional, traditional, and behavioral factors. Behavioral Finance Conference. https://papers.ssrn. com/sol3/papers.cfm?abstract_id=2845963. Accessed 05 May 2017.

Kritzman, Mark, Sébastien Page, and David Turkington. 2010. In Defense of Optimization: The Fallacy of 1/N. Financial Analysts Journal 66 (2): 31-39. https://doi.org/10.2469/faj.v66.n2.6.

Merton, Robert C. 1969. Lifetime portfolio selection under uncertainty: The continuous-time case. Review of Economics and Statistics 51 (3): $247-257$

O'Brien, John. 2006. Rebalancing: A Tool for Managing Portfolio Risk. Journal of Financial Service Professionals 60 (3): 62-68.

Oehler, Andreas. 2015. Digitale Welt und Finanzen. Zahlungsdienste und Finanzberatung unter einer Digitalen Agenda. Berlin: Veröffentlichungen des Sachverständigenrats für Verbraucherfragen.

Oehler, Andres, and Hans P. Wanger. 2019. Household portfolio optimization with XTFs? An empirical study using the SHS-base. Research in International Business and Finance, forthcoming.

Oehler, Andres, and Matthias Horn. 2020. Behavioural Portfolio Theory Revisited: Lessons Learned from the Field. Accounting and Finance, forthcoming.

Oehler, Andres, and Matthias Horn. 2019. Does Households' Wealth Predict the Efficiency of their Asset Mix? Empirical Evidence. Review of Behavioral Economics 6 (3): 249-282.

Oehler, Andreas, Matthias Horn, and Stefan Wendt. 2016. Was taugt die Finanzberatung durch Robo-Advisors wirklich? Der Neue Finanzberater 2: 28-29.
Oehler, Andreas, Marco Rummer, Thomas Walker, and Stefan Wendt. 2007. Are Investors Home Biased? Evidence from Germany. In Diversification and Portfolio Management of Mutual Funds, ed. Greg N. Gregoriou, 55-77. Houndmills: Palgrave MacMillan.

Perold, Andre F., and William F. Sharpe. 1988. Dynamic Strategies for Asset Allocation. Financial Analysts Journal 44 (1): 16-27. https:// doi.org/10.2469/faj.v44.n1.16.

Pézier, Jacques, and Anthony White. 2006. The Relative Merits of Investable Hedge Fund Indices and of Funds of Hedge Funds in Optimal Passive Portfolios. ICMA Centre Discussion Papers in Finance DP2006-10. Henley Business School, Reading University.

Pliska, Stanley R., and Kiyoshi Suzuki. 2004. Optimal Tracking for Asset Allocation with Fixed and Proportional Transaction Costs. Quantitative Finance 4 (2): 233-243. https://doi.org/10.1080/1469768040 0000027.

Polkovnichenko, Valery. 2005. Household Portfolio Diversification: A Case for Rank Dependent Preferences. Review of Financial Studies 18 (4): 1467-1502. https://doi.org/10.1093/rfs/hhi033.

Pratt, John W. 1964. Risk Aversion in the Small and in the Large. Econometrica 32: 122-136. https://doi.org/10.2307/1913738.

Scott, Robert C., and Philipp A. Horvath. 1980. On the Direction of Preference for Moments of Higher Order than the Variance. Journal of Finance 35 (4): 915-919.

Shefrin, Hersh, and Meir Statman. 2000. Behavioral Portfolio Theory. Journal of Financial and Quantitative Analysis 35 (2): 127-151.

Simson, Elroy, and Christophe Spaenjers. 2015. The investment performance of art and other collectibles. In Risk and Uncertainty in the Art World, ed. Anna Dempster, 219-238. London: Bloomsbury.

Statman, Meir. 2002. How much diversification is enough? https://ssrn. com/abstract=365241. Accessed 12 May 2019.

Tokat, Yesim, and Nelson W. Wicas. 2007. Portfolio Rebalancing in Theory and Practice. Journal of Investing 16 (2): 52-59. https:// doi.org/10.3905/joi.2007.686411.

Tsai, Cindy S.-Y. 2001. Rebalancing Diversified Portfolios of Various Risk Profiles. Journal of Financial Planning 14: 104-110.

Tu, Jun, and Goufu Zhou. 2011. Markowitz meets Talmud: A combination of sophisticated and naïve diversification strategies. Journal of Financial Economics 99 (1): 204-215. https://doi.org/10.1016/j. jineco.2010.08.013.

Vanguard Research. 2015. Best practices for portfolio rebalancing. Available at https://www.vanguard.com/pdf/ISGPORE.pdf. Accessed 12.07.2019.

Von Gaudecker, Hans-Martin. 2015. How Does Household Portfolio Diversification Vary with Financial Literacy and Financial Advice? Journal of Finance 70: 489-506.

Von Kalckreuth, Ulf, Martin Eisele, Julia Le Blanc, Tobias Schmidt, and Junyi Zhu. 2012. The PHF: a comprehensive panel survey on household finances and wealth in Germany. Deutsche Bundesbank, Discussion Paper 13/2012.

Publisher's Note Springer Nature remains neutral with regard to jurisdictional claims in published maps and institutional affiliations.

Dr. Matthias Horn is Research and Teaching Assistant at the Department of Finance at Bamberg University, Germany, where he received his $\mathrm{PhD}$ in 2018. His fields of interest include empirical and behavioral finance, risk management, asset pricing, household finance and FinTech.

Prof. Dr. Andreas Oehler is Full Professor and has held the Chair of Finance at Bamberg University since 1994. He received his PhD at the University of Mannheim and his Habilitation degree at the University of Hagen. He has published widely, in particular in the area of credit risk management, banking, behavioral and empirical finance and 
investor protection. His fields of interest also include financial markets, retirement provisions/funded pension plans, pension systems, consumer protection, personal finance and household finance. Since 2012, he has been Director of the Research Centre 'Household Finance and Financial Literacy'. He is member of various expert committees, including Chairman of the Board of the Stiftung Warentest, Germany's leading product-testing institute. 